\title{
Social adjustment after closed head injury: a further follow-up seven years after injury
}

\author{
MICHAEL ODDY, ${ }^{*}$ TONY COUGHLAN, $\dagger$ ANDREW TYERMAN, $\ddagger$ DAVID JENKINS $\ddagger$ \\ From Leybourne Grange, West Malling, ${ }^{*}$ St James University Hospital, Leeds, $\uparrow$ Wolfson Medical \\ Rehabilitation Centre, London, $\ddagger U K$
}

SUMMARY A group of severely head injured patients were reassessed 7 years after injury. This group was the same as that previously reported 2 years after injury. There was no change in their physical or cognitive status; personality problems were still commonly reported but the less disabled had made further progress in returning to their former level of vocational and social activity.

In recent years there have been numerous studies documenting various aspects of recovery in the first one or two years following severe head injury. ${ }^{1-3}$ Many of these studies have highlighted the extensive psychosocial consequences of residual disability. Both the impact upon the family and overall social adjustment have been shown to be closely associated with the degree of cognitive impairment and personality change. ${ }^{4-6}$

In 1980 Weddell et al ${ }^{7}$ reported upon the social adjustment of 44 young adults, previously treated at the Wolfson Medical Rehabilitation Centre in London, approximately two years after very severe head injuries. Marked changes in occupational status, leisure activities, social contacts and family life were noted. However, in spite of the numerous problems arising from residual disability reported by their close relatives, both the patient and relatives had in most cases already made some successful adaptations to their altered situation.

It is generally acknowledged that the greater part of recovery of function occurs during the first 6 months after injury, associated with physical repair of the brain. ${ }^{8}$ This period of relatively rapid progress incorporates stages one and two of the three stage process of recovery proposed by Bond. ${ }^{9}$ Bond suggested that in the third stage, which may continue for many months, the patient and relatives adapt to the residual disability. However, clinical impression,

Address for reprint requests: Dr Michael Oddy, Psychology Department, Leybourne Grange, West Malling, Kent, ME19 5HS, UK.

Received 30 July 1984 and in revised form 14 November 1984 . Accepted 17 November 1984 supported by case reports ${ }^{10}$ suggests that this process of adaptation may continue over a period of years rather than months. While perhaps only rarely sufficient to alter radically the overall outcome," successful adaptation may conceivably serve to improve the quality of life of the individual and alleviate some of the burden upon the relatives. Unfortunately there are, as yet, few systematic prospective studies of sufficient length and depth to evaluate either the nature or the practical implications of such adaptation. The present study aims to address this problem by reporting upon a further long-term follow-up of the group of very severely head injured patients previously described by Weddell et al. ${ }^{7}$

\section{Subjects and method}

The subjects had received severe closed head injuries approximately seven years earlier and had previously been followed-up two years after the injury. ${ }^{7}$ The subjects for the two year follow-up were drawn from the Wolfson Medical Rehabilitation Centre, a rehabilitation unit for the neurologically disabled, and met the following criteria (1) post-traumatic amnesia of more than 7 days (2) age was 16-39 years at the time of the accident (3) the accident occurred between August 1974 and June 1976, and (4) the patient lived within London and the Home Counties. Fifty such subjects were identified, of whom two were excluded-one because of previous mental subnormality and the other because of previous severe psychological disturbance. Forty-four ( 31 male, 13 female) of the remaining 48 attended for the two-year follow-up with a close relative. We have subsequently attempted to follow-up the 48 victims who were eligible for the first study. Thirty-four ( 27 male, 7 female) attended for follow-up, including one who had declined to participate in the first study. Twentyeight relatives also attended, three of these without the 
Table 1 Symptoms reported by patients and relatives seven years after head injury

\begin{tabular}{llll}
\hline Patients & $\%$ & Relatives & $\%$ \\
\hline Trouble remembering things & 53 & Trouble remembering things & 79 \\
Difficulty concentrating & 46 & Difficulty concentrating & 50 \\
Easily affected by alcohol & 38 & Difficulty speaking & 50 \\
Often knocks things over & 31 & Easily affected by alcohol & 43 \\
Often loses temper & 31 & Difficulty in becoming interested & 43 \\
Difficulty becoming interested & 28 & Becomes tired easily & 43 \\
Likes to keep things tidy & 28 & Often impatient & 43 \\
Sometimes loses way & 28 & Sometimes behaves childishly & 40 \\
Eyesight problems & 28 & Likes to keep things tidy & 40 \\
Difficulty following conversation & 28 & Refuses to admit difficulties & \\
\hline
\end{tabular}

patient. In most cases the relatives were those who had participated in the first study, but in a few cases they were new (chiefly spouses of the few who had married since the injury). The time between injury and follow-up ranged from 6.5 to 7.8 years, median 7.0 years. The head-injured patients were examined and rated on the Bond Neurophysical Scale (Bond 1975). They were interviewed briefly about the behavioural, cognitive and social sequelae of the accident and where time and/or their condition permitted, asked to complete two intellectual tests: Raven's Progressive Matrices ${ }^{13}$ and the Synomyns section of the Mill Hill Vocabulary Scale. ${ }^{14}$ The relatives were interviewed about the social adjustment of the subject using the semistructured procedure described by Oddy et al ${ }^{15}$ and also asked about his or her memory and behaviour. In addition, at this seven year stage, both subject and relative were asked to complete a symptom checklist concerning recent physical, cognitive and behavioural symptoms. The emotional state of both subject and relative was also assessed, by asking each to complete the Wimbledon Self Report Scale, an unpublished adjective checklist designed to detect emotional disturbance irrespective of the presence of physical disability or illness.

\section{Results}

Where mean values are quoted, standard deviations are given immediately afterwards in parentheses.

\section{Physical status}

At two years the head injury patients $(n=44)$ achieved a mean rating on the Bond Neurophysical Scale of 3.8 (3.8). The smaller groups of 33 patients who were assessed at both follow-ups achieved a mean score of $4 \cdot 1(4 \cdot 0)$ at two years and of $3 \cdot 5(2 \cdot 9)$ at seven years, but the improvement was not significant (paired $t$ test, $\mathrm{p}>0.05$ ). The physical disabilities of these subjects ranged between "none" and "wheelchair bound" at both two and seven year follow-ups. A typical manner in which a score of four was obtained was a hemiparesis ( 3 points) and a mild dysarthria (1 point). An example of a patient scoring three points was a woman with a hearing loss in one ear ( 2 points) and anosmia ( 1 point).

\section{Cognitive status}

Scores on Raven's Progressive Matrices and on the
Mill Hill Vocabulary test were converted into IQs by use of Peck's Tables. ${ }^{16}$ At two years the head injury patients $(\mathrm{N}=42)$ achieved a mean IQ on Matrices of $98 \cdot 2(18 \cdot 1)$. The smaller sample $(\mathrm{N}=31)$ assessed on both follow-ups achieved mean IQs of 97.4 $(19.2)$ at two years and $99.3(19.2)$ at seven years. Only 32 of the patients were assessed on vocabulary at two years and they achieved a mean IQ of 93.6 (13.6). The smaller sample $(N=23)$ assessed at both follow-ups achieved mean IQs of $93.4(13.8)$ at two years and $91.0(11.8)$ at seven years. In neither test was the difference between follow-ups significant (paired $t$ tests, $\mathrm{p}>0.05$ ). The degree of change on Matrices ranged between an increase of 21 points to a decrease of 29 points at seven years, though the majority of changes $(61 \%)$ were no greater than 10 points. On the Vocabulary Scale the changes ranged between an increase of 21 points to a decrease of 16 points, $87 \%$ being within 10 points. Difficulty in remembering and in concentrating were the most commonly reported persisting sequelae according to both the patients and their relatives (table 1).

\section{Personality}

Thirty-one out of $44(71 \%)$ relatives had reported some personality change in the patient at two years, the most common changes being increased irritability $(39 \%)$ and more affectionate behaviour $(18 \%)$. At seven years, the length of time since the accident and the fact that some relative had not known the patient prior to their injury made it less feasible to ask about personality change, so only current behaviour/personality was assessed. Impatience, difficulty in becoming interested in things, childish behaviour, a need to keep things tidy and loss of temper were most commonly reported by relatives (table 1). A similar picture emerged from the subjects themselves, though childish behaviour was less likely to be reported.

Work

We were able to determine the occupations of 43 of the head injury patients at both two and seven years 
Table 2 Occupational status

\begin{tabular}{llllll}
\hline & $\begin{array}{l}\text { Return to former } \\
\text { job/normal career } \\
\text { progression }\end{array}$ & $\begin{array}{l}\text { Full-time work at } \\
\text { a lower level }\end{array}$ & Housewives & $\begin{array}{l}\text { In and out of } \\
\text { jobs/psysiotherapy }\end{array}$ & Day centre \\
\hline 2 year assessment & 5 & 11 & 3 & 5 & 9 \\
7 year assessment & 9 & 6 & 5 & 3 & 8 \\
\hline
\end{tabular}

after injury. The distribution is shown in table 2 . Four more subjects had returned to their former employment at seven years, all of whom had been working in some capacity at two years. They included a mining engineer who had initially been confined to a desk job and a double-glazing fitter who had originally returned to less exacting duties. None of the patients working at two years were out of work at seven, though many had had changes of job before finding a suitable niche and a few still seemed in precarious positions. Those who were unemployed at two years remained so at seven. Some, who had been attending day centres at two years, now stayed at home; conversely some who were previously at home now attended a day centre. In two cases parents were taking the subject to work and keeping him occupied with trivial tasks. In one case the son did unnecessary filing jobs. In the other the father had sold his engineering business and bought a pottery of which the son was notionally the proprietor but did only minor tasks, a manager being employed to run the place.

\section{Social and leisure activities}

We found a dearth of interests and leisure activities, particularly amongst those unable to work. Boredom, although reported by some, did not appear to be the inevitable result as many patients appeared, to their families, to be reasonably content to lead rather inactive lives. Loneliness was the greater burden. Social isolation was a major problem at the early follow-up and this had certainly not improved, at least for those unable to work. About half had only very limited contact with friends. Sixty per cent had no girl or boy friends and this was commonly mentioned by patients and relatives as a major problem. For some, girl friends had lasted the first two years following their injury but had withdrawn from the scene by the time of the later assessment. Of those married at the time of injury, two had separated but three had remained married and in each case the relationship seemed to be satisfactory. Five patients had married during the period between follow-ups. All were patients who were able to work.

\section{Emotional disorder}

About $25 \%$ of relatives and patients reported that the latter often suffered from anxiety or tension but only $10 \%(3 / 30)$ of them displayed a clinical level of emotional disturbance (anxiety or depression) on the Wimbledon Self Report Scale. Seventeen per cent $(4 / 23)$ of relatives were also classified as disturbed on this scale, but neither for the patients nor their relatives was the incidence significantly higher than that of $8 \%$ found in general population sample by Coughlan and Storey (personal communication) using the same measure. In line with the established association between unemployment and emotional disorder ${ }^{17}$ none of the head injured patients or their relatives classified as disturbed were in paid employment.

\section{Discussion}

We have attempted to follow up the sample of severely head injured patients previously assessed two years after their injuries by Weddell et al. ${ }^{7}$ We were unable to reassess their entire sample but those we did see were, at two years, typical of the larger sample in neurophysical status and intellectual abilities. Our general impression is that the disabilities and social relationships of the patients have changed little over a further five years, though improvements have occurred for a few-mainly those who had already made good progress at the two year stage.

The subjects of this study were all under 40 years of age when they sustained their injuries and most were well under 30 years. There is clear and consistent evidence that with increasing age recovery from head injury is poorer. This, together with the fact that for older victims the burden of care would be likely to fall entirely on the spouse, suggests that the picture would be much more dismal for those sustaining injury later in life. The subjects in this study lived predominantly with their parents. Even without the possibly greater role of conflicts and emotional difficulties for spouses than for parents, there is the simple fact that a person normally has two parents but only one spouse. Where the spouse has children to cope with as well as the head injured person the problems can be still greater. It is therefore likely that the problems indicated in this study considerably underestimate those that would exist after comparable injuries in older people. 
Overall there was no significant change in neurophysical status and, as well as impairments of limb control, dysarthria and tiredness were common. Headaches, blackouts and other somatic complaints were infrequent. A few families were continuing to organise daily rehabilitation regimes for the patients though sometimes more to provide activity than with the belief that useful improvement would occur. One young man who had been wheelchair bound at two years had made walking his goal and after a further five years ceaseless effort by himself and his family could walk very slowly and unsteadily on two crutches. On the whole, there had been a switch away from physical activities to more creative exercises such as writing stories, drawing, photography or playing musical instruments.

Performance on intellectual tests also changed little between the follow-ups. The extent to which individual scores reflected impairments was difficult to assess but comparison of scores with previous occupations or academic achievement indicated marked impairment in $13 / 32(41 \%)$ at seven years. A few subjects displayed a considerably better or worse performance than they had done at two years, but the reasons for these changes were unclear. The test-retest reliability of the tests for such a long time period is not known. The hypothesis that sizeable improvements would be more likely amongst those in employment and deterioration more likely amongst the unemployed was not supported by our data, though the numbers were very small.

The extent to which personality change persisted was not assessed directly, but the incidence of various behavioural characteristics reported by the victims or their relatives suggested that long-term changes had taken place for some victims. Impatience, loss of temper, difficulty in becoming interested in things and childish behaviour were all commonly reported by relatives-characteristics which are often evident in the months following injury. Assessment of emotional disorder amongst the relatives and patients revealed a higher incidence amongst the former, but no clear evidence of an unusually high incidence in either group. Nonetheless, it appears that for a small proportion of patients the head injury does trigger persistent or recurrent mood changes. A further two patients who did not complete the assessment were known to us to have suffered considerable psychiatric problems (one depression, the other severe personality disorder) requiring hospital admissions, despite having been of apparently robust mental health before the injury.

There had been no major changes in employment status. No-one without a job at two years had since obtained work, but fortunately none of those who had managed to return to work was now unemployed. Some of those working in a lower capacity at two years had managed to climb back to their original job or at least a comparable one.

It was also those who were working who had been able to rebuild their social lives and sometimes marry. On the other hand the combination of unemployment and the associated greater disability proved too big a disadvantage to overcome and their appeared few opportunities for these unfortunate people to develop a social life.

This picture suggests inertia but this was often not the case. For the first few years and in some cases still continuing, parents had managed to enrol their disabled sons and daughters into a succession of rehabilitation centres, workshops, etc. For those in a position to pay, a succession of therapists, from physiotherapists to hypnotherapists, had sometimes been consulted. Even interests and activities appeared to be in a constant state of flux as the patient lost interest in one and the parents tried desperately to interest him in another.

The limited improvements in social adjustment were largely confined to the few in work. For the rest many of the problems appear to be those familiar to any unemployed person; the lack of any time structure or of a network of friends, the lack of goals to attain or of opportunities to show competence and the absence of any source of identity or status. In addition to these familiar problems associated with unemployment the head injured person has difficulty in maintaining established friendships built up over many years not only because of enforced withdrawal from their social network but also as a result of often disturbing personality changes. Opportunities for expanding leisure activities to compensate to some extent for the loss of employment are also restricted by the loss of previous skills, the lack of initiative and interest and for the more severely disabled, problems of mobility and inadequate facilities.

These are problems with which the family are clearly struggling in their efforts to provide for as many of the needs as possible. In spite of their resourcefulness it is apparent that the prospects for further improvement in social adjustment is in most cases limited after the first two years following severe head injury. The need for the continued availability of expert professional guidance and support is evident. With the development of the selfhelp group Headway (the National Head Injuries Association) the patient and family are more likely to receive informed support. However current occupational and residential provision for the severely disabled remains hopelessly inadequate. New initiatives such as the Transitional Living Center ${ }^{18}$ must 
be developed and evaluated, as there are reports of some significant benefits to be gleaned from psychologically-oriented rehabilitation programmes, focusing on the promotion of cognitive, social and occupational skills. ${ }^{1819}$

\section{References}

' Brooks DN, Aughton ME. Cognitive recovery during the first year after severe head injury. Int Rehabil Med 1979;1:166-72.

${ }^{2}$ Levin HS, Grossman RG, Rose JE, Teasdale MB. Long-term neuropsychological outcome of closed head injury. J Neurosurg 1979;50:412-22.

${ }^{3}$ Najenson T, Groswasser Z, Mendelson L, Hackett P. Rehabilitation outcome of brain damaged patients after severe head injury. Int Rehabil Med 1980;2:1722.

${ }^{4}$ Lundholm J, Jepson BN, Thorndal G. The late neurological, psychological and social aspects of severe traumatic coma. Scand J Rehabil Med 1975;7:97-100.

s Oddy M, Humphrey M. Social recovery during the year following severe head injury. J Neurol Neurosurg Psychiatry 1980;43:798-802.

- McKinlay WW, Brooks DN, Bond MR, Martinage DP, Marshall MM. The short-term outcome of severe blunt-head injury as reported by the relatives of the injured persons. J Neurol Neurosurg Psychiatry 1981;44:527-33.

7 Weddell R, Oddy M, Jenkins D. Social adjustment after rehabilitation: a two year follow-up of patient with severe head injury. Psychol Med 1980;10:257-63.

${ }^{8}$ Bond MR Brooks DN. Understanding the process of recovery as a basis for the investigation of rehabilita- tion for the brain injured. Scand $J$ Rehabil Med 1976;8: 127-33.

${ }^{9}$ Bond MR. The stages of recovery from severe head injury with special reference to late outcome. Int Rehabil Med 1970;1:155-9.

${ }^{10}$ Brown JC. Late recovery from head injury: case report and review. Psychol Med 1975;5:239-48.

" Jennett B, Snoek, J, Bond MR, Brooks DN. Disability after severe head injury: observations on the use of the Glasgow Outcome Scale. J Neurol Neurosurg Psychiatry 1981;44:285-93.

12 Bond M. Assessment of the psychosocial outcome after severe head injury. In: Outcome of Severe Damage to the CNS Ciba Foundation Symposium 1975;34:14153.

${ }^{13}$ Raven J. Guide to Standard Progressive Matrices. London, Lewis 1960.

${ }^{14}$ Raven JC. Guide to using the Mill Hill Vocabulary Scale with the Progressive Matrices Scale. London, Lewis 1965.

is Oddy M, Humphrey ME, Utley D. Subjective impairment and social recovery after closed head injury. $J$ Neurol Neurosurg Psychiatry 1978;41:611-6.

${ }^{16}$ Peck D. The Conversion of progressive matrices and Mill Hill Vocabulary Raw Scores into Deviation IQs. J Clin Psychol 1970;26:68-70.

17 Jahoda M. Employment and Unemployment: a socialpsychological analysis. London; Cambridge University Press 1982.

${ }^{18}$ Prigatano GP, Fordyce DJ, Zeiner HK, Rodeche JR, Pepping M, Wood BC. Neuropsychological rehabilitation after closed head injury in young adults. J Neurol Neurosurg Psychiatry 1984;47:505-13.

${ }^{14}$ Rosenbaum M, Lipsitz N, Abraham J, Najenson T. A description of an intensive treatment project for the rehabilitation of severely brain-injured soldiers. Scand J Rehabil Med 1978;10:1-6. 